\title{
A Conceptual Analysis of Macro Corruption: Dimensions and Forward and Backward Linkages
}

\author{
Ahmed Sakr Ashour \\ Professor at Department of Business Administration \\ Alexandria University, Alexandria, Egypt \\ E-mail: a.sakrashour@gmail.com \\ Hoda Saad AboRemila \\ Associate Professor at Department of Economics \\ Ahram Canadian University, Cairo, Egypt \\ E-mail: hodaa@outlook.it
}

Received: May 4, 2019 Accepted: May 30, 2019 Online published: June 26, 2019

doi:10.5296/jpag.v9i2.14983ＵRL: https://doi.org/10.5296/jpag.v9i2.14983

\begin{abstract}
To fill the gap in the macro analysis of corruption an attempt was made to formulate a conceptual framework that differentiates four types of macro corruption: state capture, political, bureaucratic and financial/corporate. The economic consequences or forward linkages are: growth, inclusiveness and sustainability of development. The macro institutional determinants constituting the backward linkages of each type are delineated. The research implications of the macro perspective and proposed framework were discussed. Implications of the findings for theory, research and reform policies addressing macro corruption issues were discussed.
\end{abstract}

Keywords: macro corruption - state-capture corruption - political corruption - aggregate bureaucratic corruption - financial corruption - economic development - economic growth economic inclusiveness - sustainable development

\section{Introduction}

Over the last three decades, the economic analysis of corruption has been gaining greater interest among academics, policy makers and international organizations. This is due to the ability of corruption to influence and penetrate the very roots of an economy through eroding 
property rights, distorting economic forces, inflicting and diverting public policies and straining political institutions. Economists have been interested for decades in trying to explain corruption and examine its economic consequences.

The literature on the economic impact of corruption at the aggregate level has been primarily focusing on economic growth (e.g. Hodge, Shanker, Rao and Duhs, 2011; Kaufmann and Wei, 1999; Mauro, 1995, 1997, 1998; Mo, 2001; Pellegrini and Gerlagh, 2004; Tanzi, 1998; Ugur and Dasgupta, 2011) and foreign investment and much less on other dimensions of economic development pertinent to inclusiveness such as poverty reduction, equity and distribution of economic opportunities, wealth, and employment.

There are conflicting arguments and results in the literature; some argue for the positive effect of corruption on growth due to the enhanced efficiency of the government procedure through lubricating the stiff wheels of its rigid administration. They suggest that this helps speeding up investment and growth (Acemoglu and Verdier, 1998; Beck and Maher, 1986; Huntington, 1968; Leff, 1964; Lui, 1985). Others provide the opposite views and argue for the negative influence of corruption on government efficiency and therefore growth (Aidt, 2003; Bardhan, 1997; Kaufmann, 1997; Kaufmann and Wei, 1999; Seyf, 2001). Besides, the efficiency effect argument ignores the dynamic and total perspectives of the context in which corruption takes place (Hodge et al., 2011; Myrdal, 1968).

The problem of the macroeconomic analysis of corruption to a certain extent lies in the lack of a conceptual base that defines and analyzes the dimensions or components of corruption at that level of analysis. The research conducted on the economic consequences and antecedents of corruption, besides lacking a solid macro theory and related variables deals with corruption in a fragmented way. Moreover, with the exception of Aidt (2010) on corruption and sustainable development, and Hodge et al. (2011) on corruption and growth, most of the studies on the relationship between corruption and development did not fully examine the nature of the linkages. Since the available evidence was not originated from or based on theoretical foundation, it has not differentiated between various levels of results. Thus, in some studies investment in physical and human capital, government expenditure and FDI were taken as development indicators; while in others growth and per capita income were used as dependent variables representing development.

Similarly, the studies on the factors impacting corruption suffer from various conceptual and methodological shortcomings. No theory exists on the macro dimensions or components of corruption that influence their occurrence at that level. The definition of corruption (abuse of authority to acquire personal/private gain) is more pertinent to the micro level, no definition is provided for the macro level of analysis.

With the conceptual/theoretical foundations set at the appropriate level of analysis and the dependent variables (in our case the dimensions of development as the end results or consequences of corruption), the important macro corruption dimensions are defined properly and the factors leading to corruption are identified; then further examination of moderator, intervening or channel variables mediating the linkages could be additionally developed or integrated to enrich the conceptual framework and future empirical findings. 


\section{Macrothink}

Journal of Public Administration and Governance

ISSN 2161-7104

2019, Vol. 9, No. 2

Over the last decade and half, the literature on corruption and its associated variables have made advances in identifying some of these variables but with a major focus on economic growth. The variables of these studies were selected in a fragmented way. This was due to lack of theory and inadequate choice of the dependent variables of concern. With the focus on corruption at the aggregate or macro level and its impact on inclusive growth and sustainable development, richer, more meaningful and useful results could be obtained.

Given the above gaps in corruption research, the present study has the following objectives:

1. To provide a conceptual/theoretical framework that identifies dimensions of macro corruption along with their forward and backward linkages.

2. To briefly discuss the research and reform policy implications of the proposed framework.

\section{A Proposed Conceptual Framework on the Forward and Backward Linkages of Macro Corruption}

In the following figure, the key factors around which the proposed framework is based are defined and discussed and the linkages identified.

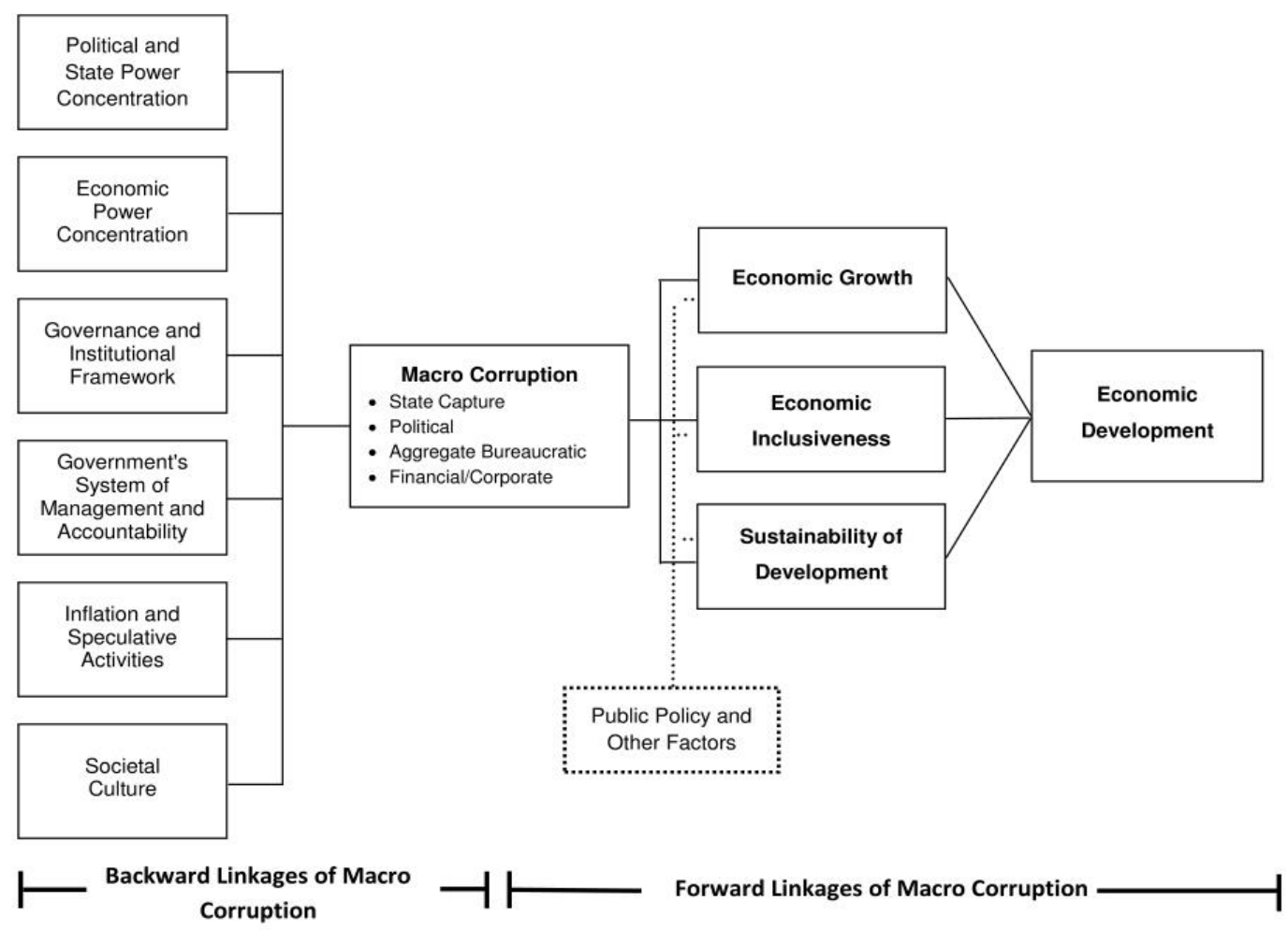

Figure 1. Conceptual Framework of Economic and Institutional Linkages of Macro Corruption

\subsection{Macro Corruption and Its Dimensions}

Most of the literature on corruption defines it as "the abuse of public office to serve private/personal gains". The gains are extracted from the principle (society), who is unable to 
hold the agent (state, public employee or official) accountable due to high monitoring costs (e.g. Groenendijk, 1997; Ugur and Dasgupta, 2011). The definition focuses on bureaucratic corruption in the government and also the abuse of political authority by high level policy makers such as ministers, high ministry officials and political representatives (e.g. parliamentarians) at the various levels of government. The reference to the high monitoring cost associated with weak accountability assumes that the principal possesses power and is himself free of corruption. In reality the principal is deputized or represented by top state officials such as the head of the state/government or its ministers and the legislative body with an assumption that they have the will to curb corruption but are constrained by the cost or lack of knowledge on how to do it. This view does not, as most economic analysis of corruption, consider that the so-called principal, the principal's representatives and/or the state oversight bodies may be infected themselves with corruption as in the case of state capture. Most of the literature that confines the definition to the abuse of public authority for private or personal gain attributes that to weak institutions and gaps in the accountability framework. Within this analysis, differentiation is made between political, grand and petty corruption and also between the different types of corruption taking place in the state bureaucracy (e.g. bribery, nepotism, trading in office, embezzlement...etc.). The analysis does not differentiate micro from macro corruption and it oftentimes mixes the two.

If corruption is to be related to macroeconomic development indicators, it should be defined and analyzed at that level of analysis, the aggregate/macro level. This differentiation would not only enable better understanding of the phenomenon, but would have implications for research, reform and policy making. Therefore, we can define macro corruption as "the abuse of power by some state institutions or minority segments of political or economic actors that results in capturing gains for these institutions or segments at the expense of the interest of the wider public or the society at large". According to this definition macro corruption results in the redirection and distortion of development policies; diversion and looting of national and state assets; distortion of economic and market forces; increasing transaction costs at the aggregate level and undermining the protection of property rights.

The above definition enables us to delineate the following dimensions or types of macro corruption:

\subsubsection{State Capture Corruption}

It represents capturing key state institutions particularly policy-making bodies (cabinet or key ministries or institutions) and the legislative branch at the central and local levels by some elite groups. The purpose is to direct the public policies, legislations and regulations and to extract benefits that serve the interest of political/economic elite(s) (e.g. political parties, business groups, the military or social or ethnic groups). State capture corruption is different from ordinary forms of corruption in that it occurs when unclear boundaries between the political and business interests of state institutions or officials are exploited by specific elite groups and state officials for their mutual benefits and when such groups, institutions and officials control the policy making mechanisms of the state to assure the flow 
of these benefits. It is the most harmful form of corruption as it entails subverting the critical organs of the state and the entire political process (Broadman and Recanatini, 2001) to ensure that state policies/regulations are favorable to the elite groups and institutions engaging in this type of control over the state and the political system.

\subsubsection{Political Corruption}

It represents the acquisition of political power through illegal and illegitimate means such as bribery of voters, forging elections, military or political coupe, oppressing political voice/participation, monopolizing political authority (lack of power circulation) and using lobbying tactics to serve the interests of a selected few against those of the majority of the public. The purpose is to acquire political leverage that can be translated into economic gains and to enable those who monopolize political/economic power to secure and enhance such power and increase their economic rent. The literature focusing on the type of corruption that infects the political system (political corruption and state capture) (referred to by the World Bank, 2010) has focused primarily on that system and its institutions with much less interest in its macroeconomic consequences. Most of the research on the economic consequences of political corruption and state capture used case studies and anecdotal data of particular country rulers and the wealth they looted from their countries as in the majority of such literature on Africa (e.g. Ake, 1996; Leith and Lofchie, 1991). Studies on corruption conducted by political scientists tended to emphasize political and institutional variables with much less focus on complex development or economic variables. On the other hand, economic studies of corruption focused more on economic variables and much less on macro political variables (e.g. Aidt, 2009, 2010; Venard (2013). There seem to be reluctance to fully cross boundaries of disciplines even though that corruption at the aggregate or macro level is a complex multifaceted phenomenon that requires an inter-and multi-disciplinary approaches.

\subsubsection{Aggregate Bureaucratic Corruption}

It refers to the degree to which grand and petty corruption is widespread in the government and the extent to which it has penetrated various levels of its body. Extensive prevalence of such corruption means extracting benefits from bureaucratic authority. It reflects on the quality, accessibility and equity of public services. The various types (grand and petty) and the different modalities of corruption (bribery, nepotism, embezzlement, extortion, trading in office...etc.) are likely to have different types of impact on the performance of public organizations and on the various public and service recipients they deal with, depending on the nature of the service (i.e. regulatory or support services) and the type of recipients (investors, private sector, households, regular citizens and marginalized groups). The prevalence of aggregate bureaucratic corruption pertains to the overall deviation from integrity, honesty and other ethical principles that should govern the practices of the government employees.

\subsubsection{Financial/Corporate Sector Corruption}

This type of corruption, if present and widespread among financial institutions such as 
banks, stock exchange and other financial institutions in the financial sector (e.g. Investment funds, holding companies and insurance companies), and the corporate sector in general can hamper the economy greatly. The history of national and international financial crises is full of how particular groups of speculators, market manipulators and executives can bring the financial sector and the whole economy down. Through such manipulative, speculative and rentier activities, they produce widespread harms for the financial sector and the majority of its smaller actors as well as for the economy as a whole.

\subsection{Forward Economic Linkages of Macro Corruption}

The studies on the macroeconomic consequences of corruption, only recently started to examine the impact of corruption or related institutional variables on dimensions of economic development other than growth; inclusive growth and sustainable development (e.g. Aidt, 2010; Pritchett and Werker, 2012; Venard, 2013). There is a growing consensus in the literature that corruption (in general) is responsible for the meager development achievement attained by certain regions such as Africa (e.g. Humphreys and Bates, 2005) and is responsible for the generation of poverty traps and economic inequity (e.g. Andrig and Moene, 1990; Blackburn et al., 2006, 2008). Most of the studies focused primarily on economic growth, despite that growth while being a necessary condition for development, are not sufficient for or equivalent to it. A great deal of the research on the relationship between corruption and economic development has been absorbed by the debate on whether corruption contributes to or hinders growth. This debate have diverted the attention away from providing conceptual clarification on the nature of aggregate or macro corruption and its linkages or paths to various economic development variables. It is well established now that growth by itself does not necessarily produce the type of economic development that benefits the wide base of the society, particularly the needy and marginalized, nor that it is by itself assures sustainability of development in the longer term. We therefore decompose economic development into three key dimensions: growth, inclusiveness of growth and sustainability of development. Although there is some mutual influence between these dimensions (e.g. inclusive growth can contribute to the sustainability of development), it is important to deal with each dimension separately for conceptual clarity and also for research and policy implications. We define and discuss these three dimensions in the following.

\subsubsection{Economic Growth}

The concept of economic growth refers to the increase in the per capita real income of the country and is measured by the percent change in that per capita income. Positive growth rate of a country in a particular period results from the greater increase of the gross national product than the increase in the population during that period. When the rate of growth is enhanced and accelerated it can surpass the population increase. To contribute to development (to make tangible change in the economy and to impact on people's lives), growth needs to be enhanced and maintained over a significant period of time. Therefore, the magnitude and trend of the rate of growth over time is important for realizing its developmental impact. Policies that try to achieve that usually rely on expanding the productive base of the economy through increasing investment, production capacities, 
innovation and resource utilization as well as improving productivity of the factors of production in key sectors.

Intermediate Variables Contributing to Growth

Economic growth is affected by a number of intermediate variables, which constitute the prerequisites of growth. Important among these variables are the following:

- Productivity. Changes in productivity are a major determinant of growth. Improved productivity means increasing the national product relative to the factors of production utilized. It is a resultant of the productivity changes pertinent to the various factors. Total Factor Productivity (TFP) is taken nowadays to be an indicator of the growth capability of an economy. It reflects the changes in the output that cannot be explained by changes in the quantities of the various factors of production. It is the residual of the output growth after accounting for the changes in the factors of production.

- Investment. Change in the capital stock invested in economic activities is another key determinant of economic growth. It represents the change in the productive capacity of the economy. Increase in investment means enlarging this capacity which in turn results in growth in output (provided that productivity does not decline at the same or greater rate). Investment could come from local (private and public) or international sources. Foreign Direct Investment (FDI) plays an important role in accelerating growth in national economies. FDI is sensitive to the attractiveness of the investment particularly the institutional environment of the country.

- Manufacturing and Innovation Value Added. Historically, manufacturing represents the driving force of economic development since it constitutes the productive activities that contain the most value added. It is the hub for modern production technology and modern business institutions besides possessing the greatest potential for growth. Although there are now certain services that contain similar or even greater contribution to growth (i.e., knowledge and technology and innovation-based: e.g. information technology, communication, innovation-based services, research and development, education, health services, information services) manufacturing still represents a key contributor to growth for many developing countries that do not have the knowledge and technology infrastructure required for this high value-adding services. Innovation-based economic activities in manufacturing or services are becoming a key driver of accelerated growth and a major source of competitive advantages. Thus, manufacturing and innovation value added (MIVA) is an important contributor to economic growth

- Global Value Chain Participation. The share of the country in the global value chain represents the position of the country in global trade measured in value-added rather than gross terms. In the current global economy, Global Value Chain Participation (GVCP) is another important driver of economic growth. It represents the degree to which the country is integrated with the global economy in forward and backward linkages in a way that impacts its value-added activities. It reflects the extent to which a given country contributes to the global processing of goods and 
services. It can be measured by cumulating the degrees of forward and backward integration (Conceicao, Shimeles and Solignac-Lecomte, 2014).

\subsubsection{Economic Inclusiveness}

The concept of economic inclusiveness refers to the degree to which the various segments and sectors of society participate in and benefit from the growth in economic activities and their resultant outcomes. There is evidence from the experience of the fast growing emerging economies that the leap forward they achieved resulted not only from enhancing, accelerating and maintaining growth but also from making the growth inclusive. This is realized by getting the various segments, regions and sectors of the society to benefit disproportionately to their original standing on income, wealth and living standards (i.e. greater percent increase to the poor and marginalized than to wealthy and well-to-do segments and sectors). However, in many developing countries economic growth was not accompanied by such results. Looking at the situation across various countries in the world, income inequality has widened considerably since the early 1980s particularly as a result of economic liberalization and globalization policies in addition to the impact of global economic crises. As a result, there is rising interest in inclusiveness and equity in the opportunities and gains associated with economic growth. Increasing and accelerating the rate of growth does not necessarily mean better income or standard of living for all segments of the population. In many situations the opposite could take place. Thus, growth could be associated with greater poverty and less equitable distribution of opportunities, gains or income, if the increase in national product goes to and benefit only a few. The trickle-down effect theory of growth promoted by the international organizations for decades (1980s and 1990s) has been refuted by evidence. Various alternative approaches to development and growth have been promoted since the new millennium, such as pro-poor, equitable and inclusive growth and development. The experiences of the emerging economies such as Asian countries and an increasing number of economies in Latin America have provided evidence that improving public services for all segments of the population, enhancing productivity across all regions and sectors of the economy and for the various factors of production along with enhancing the income and earning capacity of the poor through targeting them, result in enhancing growth and increasing equity and inclusiveness simultaneously. Thus, inclusiveness of growth refers to the extent to which the increase in per capita real income and other non-income components (education and health) of a country is associated with improvement in the equity of the distribution of income, non-income and living standard components. We suggest that inclusiveness pertains to two key dimensions:

- Inclusiveness of key services and opportunities. This entails providing equity in the distribution and accessibility of services (quantity and quality) contributing to human capital (education and health), physical capital (infrastructure: e.g. roads, water, sewage and electricity) and security services. This could be measured through the distribution of human and physical capital and security services. It also entails equity in the opportunities represented by access to markets, resources and employment by various segments (including gender) and regions; and the existence 
of unbiased regulatory environment and support services for businesses (including small and medium enterprises) and individuals (Commission on Growth and Development, 2008) The equality of opportunities across various enterprises/firms and the empowerment of the smaller ones enable small and medium firms (which constitute the majority of business entities) to contribute to the acceleration and inclusiveness of growth as they are the greater source of employment and business innovation and growth. This is different from the pro-poor approach as it is not mainly and only concerned with the welfare of the poor but with the opportunities for the vast majority of the population and the labor force, poor and middle class alike (Ianchovichina and Lundstrom, 2009), and also large and small enterprises alike.

Institutional inclusion. The reference here is to the incorporation and integration of various economic actors in the level playing field. This requires the institutionalization and integration of the various economic activities and transactions in the formal economy. Institutionalization of economic activities and transactions helps to widen the base of the economy through enhancing connectedness among and opportunities for the various economic players. The existence of a large informal economic sector is indicative of weak inclusiveness. Besides, the marginalization of small and medium enterprises would also reflect a similar weakness.

\section{How Macro Corruption Impacts Economic Growth}

We presume that all types of macro corruption contribute negatively to the rate, speed and sustainability of growth:

- Political and state capture corruption redirects, manipulates and influences the political system and state powers to serve the interest of the elite political groups not the growth or development of the total economy. This results in redirecting and diverting state resources and government policies/programs to serve the interests of the controlling elites not necessarily the national interests. Under such conditions, growth will not be enhanced, accelerated or maintained. In the extreme cases of these types of corruption the assets of the state and the society are transferred to private groups. This limits their use in enlarging the base of productive capacities of the economy. The increase in wealth of the powerful groups/elites is not generated through productive/value adding activities, as it is acquired through corrupt deals and rent-based activities.

- Aggregate bureaucratic corruption, besides representing waste of government resources and distortion of its programs, it implies increase in cost of investment and higher transaction costs for the total economy in general. Besides, it results in diffusion and distortion of government services due to the inefficiency of government operations. Under severe bureaucratic corruption the government becomes a burden on the economy, thus hurting its growth capabilities and potential. 


\section{Macrothink}

- Financial and corporate sector corruption and the related speculative activities increase the rent-based sources of income and wealth of the elites. And, as the productive value adding activities tend to be less attractive for a larger part of the population; this hurts the enhancement, acceleration and maintenance of the growth rate. Additionally, financial sector corruption greatly hinders growth through creating disruptive and distorting forces that cause financial and economic crisis. When such corruption is penetrating and widespread, disturbs the functioning of the whole economy if it is widespread. The speculative and corrupt financial practices by financial institutions and the corporate executives are the main triggering force for these crises. Gaps, loopholes and weaknesses in the regulatory framework allow corruption and rent seeking activities to cause such collapses in the whole economy.

How Macro Corruption Impacts Economic Inclusiveness

Inclusiveness of growth widens the base of contributors and beneficiaries. It is proposed that macro level corruption impacts inclusive growth through the following linkages and mechanisms:

- State capture corruption directs state policies to serve large businesses and powerful institutions (e.g. the military) with almost total negligence of equity and equality of opportunities and with no concern to the unemployed, the poor and the small enterprises. The regulatory environment under this type of corruption is designed and implemented to serve those belonging to the clique and institutions that controls the legislative branch, the head of the state and the government cabinet as well as oversight agencies. Under such conditions public policies and the pseudo institutional and administrative reform and even economic policy reform or the anti-corruption initiatives are adopted and applied without real political will. In fact, these policies are designed in a way so that the burden avoids inflicting losses and may harm the interests of the ruling elites. The state resources and capacity are directed to serve those elites. Short term increase in the growth rate my take place, but due to these biased policies, their effects do not significantly trickle down, simply because the ruling clique did not design them to produce such effects. Income and wealth disparity increase greatly and the economy and its key sectors are controlled by the monopolies owned by the ruling elites/cliques. The poor and marginalized businesses operate in the informal sector. Illegal/illegitimate economic and rent seeking (non-value adding unproductive) activities of a large segment of the population and most economic actors become prevalent. Under such conditions, growth is stagnant or slow due to weak inclusiveness.

- Political corruption seeks to influence, manipulate or forge the elections to control the legislative branch and/or the presidency and other elected officials (e.g. local councils). The aim is to get the benefits and gains associated with these positions but more importantly to direct the decisions and policies of these bodies to serve the interests of these actors or their cronies. The poor voters are often bribed to give their vote to the wealthy candidates or those belonging to socially powerful segments, 
families or tribes. The end result of those corrupt politicians reaching these positions is the diversion of public resources and policies and the distortion of the role of the political institutions and perhaps the whole political system. As a result, development and economic policies would not be directed to serve the interests and needs of the various segments and economic actors, as the power of the corrupt officials is directed to maximize their gain while in office, and oftentimes to get them to monopolize the political arena. Gaps in democratic governance continue to increase and the whole system falls into the vicious circle trap of weak political and institutional reform and weak economic performance.

- When bureaucratic corruption is prevalent and widespread due to complex procedure, excessive regulations, red tape and weak accountability, government organizations are not only inefficient or ineffective, but also a source of waste of state resources and a burden on people and the economy. The aggregate effect of bureaucratic corruption is a delusion of government programs and budget. Rather than being a catalyst or supporter of growth and a balancing and a corrective force (rectifying market deficiencies/imbalances) to achieve equity and inclusion, governments infected intensively by such corruption, loose by definition the ability to play such roles. The government programs, which were originally initiated to achieve equity, may likely be a source of disparity and inequity. There are numerous examples of how subsidies and free government services turn to be a domain for corruption and therefore may achieve the opposite results of what they were created for. Bureaucratic corruption creates waste not only on the expenditure side but also on the revenue collection side. The result is greater budget deficit and inflated public debt that my turn to be a chronic problem resulting often in chronic inflation that mostly hurts the poor and wage earners, thus resulting in reduced equity. That chronic inflation, in addition, creates a tendency to engage in speculative activities that further fuel the original problem and ends up in further widening the income disparity and worsening inequity.

- Financial sector corruption disrupts the economy, slows down its path to growth and hurts primarily the weaker economic segments and players (e.g. workers who lose their jobs and vulnerable small enterprises that collapse and get out of the market). The losses of the rich are relative because they would likely have reserve assets. But the losses incurred by the poor tend to be relatively major, as they usually do not have anything but their working and income earning capacities. Besides, small business owners are also similarly victimized. Mazzucato (2018) indicated that the expansion of the financial sector (through money and credit creation, expansion of asset management industry and the appearance of shadow banking which operate away from the supervision of a central bank) and the financialization of the whole economy (e.g. companies financing the purchase of their sales and the repurchase of corporate sales known as buybacks) with disproportionate contribution to value represent rentier activities. They are forms of value extraction with no contribution that result in macroeconomic dysfunctions characterize contemporary capitalist economies as they 
result in massive inequitable distribution of value and wealth. In our analysis they represent a form of macro corruption.

\subsubsection{Sustainability of Economic Development}

Sustainable economic development pertains to the ability of an economy to maintain or increase the living standards through time, meaning not to compromise the living standards of the future generation by attending to those of the current generation. Growth in GDP per capita is no guarantee for long-run sustainability. Ultimately, economic development is primarily concerned with sustainable improvement in human welfare. When sustainability is not considered, it is possible that an observed increase in the growth rate of GDP per capita over a period of years may be associated with a fall in inter-temporal social and material welfare when the consequences for future generations are not considered (Aidt, 2010). Therefore, sustainable economic development is generally defined as present economic paths through which growth is realized that do not compromise the well-being of future generations (World Commission, 1987), and more specifically, when the social and material welfare of an economy does not decrease over time during the development path taken. Sustainability requires that the inter-temporal social and material welfare is not declining over time (Aidt, 2010). It implies that all the capital assets or the productive base and other life resources increase or at least does not decline over time. Capital assets representing the core of sustainability include human and social capital, financial and material assets, knowledge and technological capital, cultural and heritage assets, and ecological and natural resource assets. These various types of assets do not only represent the productive capacity of an economy, but they also include the soft assets and resources (e.g. cultural and heritage assets and aesthetic features of nature) that contribute to the welfare and happiness of people.

How Macro Corruption Impacts Sustainable Development

Corruption has the potential to undermine sustainable economic development in a variety of ways. The following delineates such impacts:

- State capture and political corruption restrict the state capacity to develop policies that foster long range development and reduce its ability to regulate and exercise control over activities that harm capital assets of a country. Sustainable development requires maintenance, preservation and suitable investment in the economy's capital assets. Corruption in the policies and institutions related to these assets would result in depletion, deterioration and lack of investment in the pertinent assets. Corruption in the political system and state policy making and regulatory institutions causes the diversion of programs and state funds designated for building capital assets of a country to serve private and usually consumption ends. The most extreme example of this is the case of Uganda in mid-1990s, where 80 percent of the funds intended for the surveyed schools by the World Bank disappeared. The privatization schemes, under this type of corruption, is likely to be loaded with kick-backs and briberies to facilitate the selling of public assets for cheap prices and returns going to the state but with private "rentier" gains captured by the corrupt officials, politicians, and buying entities. In such situations, privatization does not result in improving the capacity of 
such assets. Under this type of corruption oversight and regulatory bodies avoid exercising their power over the political and powerful business clique who influences policy making often at the highest level. There are also abundant evidence generated from research on the so called "natural resource curse", as the abundance of such resources, with the existence of rampant corruption and poorly developed political system and institutions, results in fostering "rentier" economy (e. g. Auty, 1993; Hodler, 2006; Lane and Tornell, 1996; Mehlum, Karl \& Ragnar, 2006; Robinson, Torvik \& Verdier, 2006) which crowds out investment in manufacturing and human capital. It also results in misallocating talent away from innovative activities to rent seeking (Acemoglu and Verdier, 1998; Gylfason, 2001; Papuyrakis and Reyer, 2006) and encourages growth-harming increases in government consumption (Atkinson and Hamilton, 2003).

- Aggregate bureaucratic corruption results usually in providing a disincentive to private investment as it represents additional costs to investors (Blackburn et al., 2006, 2008; Ellis and Fender, 2006; Krusell and Rios-Rull, 1996; Mauro, 1995; Murphy, Andrei \& Robert, 1991, 1993) and an implicit tax on international investors (Wei, 2000). Although bureaucratic corruption tends to increase public investment, especially inefficient capital-intensive ('white elephants") as it is associated with a stream of bribe income (Rose-Ackerman, 1999) but it is associated with poor quality of infrastructure, i.e. with investment of poorer quality. Bureaucratic corruption diverts budget programs directed to preserving and developing national assets to serve the private ends of the bureaucratic employees and officials and their cronies. For example, corrupt institutions specialized in environmental protection and regulation let go of serious violation of environmental standards by business firms. There is abundant evidence on the close association between extraction of natural resources, resource rents and corruption resulting in environmental degradation. Similarly, heritage assets and antiquities are smuggled out of the country through the complacence of the concerned officials with the smuggling parties. The same applies to research funds designated for improvement of knowledge assets that end up in paying salaries and conducting studies of no significant value; pseudo research.

- Corruption in the financial sector resulting in financial crisis represents a serious disturbance to the continuity and stability of the growth path and thus hurts the sustainability of development. The loss of assets and lack of funds to preserve other assets represent major blows to the stock of development capital. The inflation associated with the rent seeking financial manipulation and speculative gains results in damages to various appropriations to value adding productive sectors it hurts more the weak and small economic players and curtails their opportunity to grow and improve or sustain their economic position.

\subsection{Backward Institutional Linkages of Macro Corruption}

We analyze in this section the factors constituting the backward linkages of macro corruption. 
These factors belong to the concentration of power in the political, state and economic systems, the institutional framework governing state policy and decision making, government system of management and accountability, inflation and speculative activities and societal culture.

\subsubsection{Political and State Power Concentration}

Political and state systems that have mechanisms and safeguards against the monopolization of political power and that includes checks and balances along with participatory and accountability frameworks are less likely to be subject to political and state corruption. The vulnerability of the political system and state organs to corruption is reduced proportionately to the existence of these mechanisms and safeguards. Authoritarian regimes and state systems that do not separate state powers, where their accountability to the society is minimized and political officials are not subjected to the will of people, are likely to be infected by various types of corruption. Under such conditions, certain social or political groups or clans, foreign or local business interests, or segments of the population can easily get various preferential treatments or favors from the state. State institutions suffer from relative weaknesses vis-a-vis such groups or segments. When the state is ruled by some particular elite, the extraction of benefits takes place directly through the hegemony over the policy making positions in the state bodies. There is evidence that dysfunctional political institutions, due to dictatorship and concentration of political power, enable corrupt politicians to extract unpredictable rents. The less powerful economic players tend to shift from the formal to informal sector where they can find a better refuge there (Aidt, Dutta and Sena, 2005, 2008; Drury, Krieshhaus and Lusztig, 2006).

\subsubsection{Economic Power Concentration}

The degree to which economic power is concentrated in key sectors with weak accountability meaning being monopolized by a few players would likely give rise to these players exerting influence on policy making bodies of the state to influence public policies primarily to serve their interest, make gains and defuse and reduce the regulatory role of government bodies regarding their business activities. Such attempts are done through large oligarchic businesses bribing and exchanging benefits with politicians and high public officials and through eventually seeking positions in the political institutions (e.g. ruling party, parliament or government cabinet) as a means to better guarantee their influence and realize their interests. The result is greater rents for the powerful economic players and more fortification of their position in the economic and political arenas.

\subsubsection{Governance and Institutional Framework}

Gaps and weaknesses in the governance structure and the institutions which balance and regulate power distribution (political, economic or otherwise), manage the economy, regulate markets and account for the practices of the powerful players, represent ingredients for the emergence of grand political and economic corruption, including the use of state institutions to extract benefits for the powerful elites and the ruling groups. The weakness in the institutional framework will entice those groups to influence directly or indirectly 
the decision-making bodies and the practices of the government to their benefits. Lack of transparency and accountability in such framework will contribute also to the rise of bureaucratic corruption. Additionally, weakness in the institutional framework that governed liberalization of transition economies and market transformation and economic globalization of many developing countries during the last few decades have given rise to the proliferation of corrupt practices in areas such as selling state assets through privatization and concessions, extracting and squeezing tax benefits from the state and evading state regulations. Institutional weaknesses may act as drivers of both excessive regulation/interventions and corruption at the same time (Myrdal, 1968); thus getting institutional weaknesses, excessive regulations and corruption to become a vicious circle.

\subsubsection{Government System of Management and Accountability}

There are abundant analysis and evidence regarding the role of the management system, governance and the accountability system by which government organizations operate in preventing/restricting or enhancing bureaucratic corruption. Traditional public administration system that relies on elaborate and complicated rules and procedures, with no strategic or results orientation, no focus on the clients, reliance on non-transparent practices and low access to information, using line-item budget, with large discretion not accompanied by the proper accountability, and no provisions to enhance integrity and prevent corruption; are likely to be infected strongly by bureaucratic corruption especially when competence is not sought and employee wages are low. Bureaucratic corruption is determined by the gaps and loopholes in the institutional framework characterizing government administration.

\subsubsection{Inflation and Speculative Activities}

Economies characterized by high inflation due to monopolistic market structure and related business practices, ineffective fiscal and monetary policies, poor economic development policies and pervasive rent seeking activities serve to drive business groups who own assets to engage in speculative activities and government employees to compensate for the loss in real wages by engaging in corrupt practices. How the financial sector is structured and regulated determine to what extent this will limit or promote speculative, rent seeking and corruption activities that impact the whole economy. Economies so characterized are likely to be corrupted in key sectors of the economy.

\subsubsection{Societal Culture}

Countries vary in their value system, ethical norms and tolerance towards various types of corruption. Most of the literature on corruption recognizes the role of societal culture in the spread or containment of corruption. However, much little research has been done to clarify how cultural values, norms, beliefs, traditions and tribal or ethnic structure of the society affect attitudes and tolerance towards corruption and its various types. We suggest that societal culture and its various components or dimensions could play an important role in affecting types and levels of corruption at the aggregate and micro level. Religious belief systems and the extent, to which they are deeply rooted in the societal culture and expressed in daily practices, constitute an important source of the values and ethical norms towards 
wrong doing and corrupt acts.

\section{Discussion and Research Implications of the Proposed Framework}

The above framework and its associated analysis suggest that there is a need to have a new perspective on corruption and its linkages at the macro level. Macro corruption needs to be differentiated from micro corruption and this implies different dimensions and focus. Examining the macroeconomic developmental consequences of corruption needs to be based on a conceptual clarification of the nature of economic development and how macro corruption impacts it. The cumulative work done over the last two decades on this topic indicates clearly that development cannot be reduced to growth rate. Development means enhancing the opportunities, capacities, earning power and living standards for all segments and sectors of the society/economy. The focus now is on equitable or inclusive growth, not merely per capita growth as the later may hide gross inequities, which cannot be lasting or stable. There is also an equal emphasis on the long-range equity and development sustainability. Over the long run, real development is about preserving or enhancing the stock and capacity of various capital assets, which the society possesses. Inclusive growth and sustainable development are what macro corruption hurts the most. It undermines the equity among current as well as generational segments of the society. Therefore, it is about time to shift the focus on the economic impact of corruption from mere growth to the true dimension of economic development. This will not exclude corruption implications for other sub-components of development or for intermediate results such as investment, barriers to entry, allocation of public expenditures, transaction costs, and cost and quality of infrastructure projects. These are important and interesting consequences of corruption. However, they do not represent end result development indicators, nor does per capita growth.

The proposed conceptual framework and the idea of forward and backward linkages of corruption analyzed at the macro level, provides an opportunity to systematically examine the macro consequences and pre-conditions of corruption. This offers more conceptual clarity and would likely contribute to resolving the conflicting evidence and ambiguities characterizing some of the research in this area (see reviews by Aidt, 2009, 2010 and Ugur and Dasgupta, 2011). Consistency in the conceptualization and the associated level of analysis of corruption and its linkages is likely to contribute to better understanding of corruption and more effective accumulation of empirical evidence and knowledge about its nature and correlates at the various levels of its occurrence.

Most empirical analysis of corruption and its correlates has been constrained by availability of indicators and data. And, most of such data was not gathered or established based on a conceptual formulation that differentiates between macro and micro corruption. It is, therefore, worthy to invest in improving the conceptualization of corruption and in analyzing its developmental impacts along with its causes and correlates at the macro and micro levels. The previous conceptualization is a modest contribution to that end. Once enough progress has been made in this direction, data should be generated to correspond to the concepts suggested in the proposed framework. In the meantime, proxy indicators can be carefully 
selected and used, but with the qualification that the data contain proxy indicators and that results coming from their analysis would be highly tentative.

Future research could focus on a number of streams: (1) to examine the forward linkages of each type of macro corruption to the various dimensions/components of inclusive growth and sustainable development. This requires examining the intermediate channels or transmission paths through which each corruption type impacts or is associated with the particular dimensions and variables of economic development as delineated in the proposed framework; (2) similar stream of research should be conducted with regard to the factors impacting or associated with each type of macro corruption; along with examining the interaction between various socio- political, economic and institutional factors and conditions for each of the corruption types and their interactions; this is needed for the clarification of how certain types of macro corruption evolve, grow, transform, stabilize, fortify or decline (including the mechanisms and processes by which their beneficiaries engage in various types of tactics to protect their positions and gains (in this regard the quantitative research should be supplemented by qualitative and case study research to further understand the processes involved; (3) to test the relations (association, causation and its directionality; time series; comparative cross- sections of countries; and linear and non-linear) deduced from the conceptual framework suggested in this report; (4) to identify and examine intermediate contingencies/variable moderating, mediating, intervening or confounding the relations between corruption dimensions and its developmental consequences as well as its political, institutional, economic and cultural antecedents; and finally (5) to develop the appropriate measures and relevant data bases that correspond to pertinent constructs of the dimensions/variables of macro corruption and those of forward and their backward linkages. At present, a great part of the data bases (with the exception of the Governance Indicators of the World Bank) have been developed to fit multiple purposes and they contain proxy indicators that do not always fit the conceptual constructs or the level of analysis required by the proposed macro perspective.

The advancement in understanding macro aspects of corruption and its related factors should provide great help to reform and policy makers around the world particularly in countries experiencing serious development problems associated with systemic corruption at the macro level. Policy-driven studies that suit the needs of particular country/countries based on findings and conclusions derived from the above suggested research represent an additional source for advancing knowledge about corruption while at the same time helping the reform initiatives in the concerned countries.

An additional implication of the proposed analysis is in order. The emerging literature on the sectorial approach tackling corruption needs to be qualified. It is true that corruption in various sectors (e.g. health, education and infrastructure) has different features and causes. But addressing corruption in the sectors without dealing with the root causes in the state and political systems and in the government's system of management and accountability would have limited impact. The United Nations and number of other international organizations have been advocating the sectorial approach, as it is difficult to require these organizations to suggest addressing issues such as state capture or political 
corruption. These organizations circumvent such issues as they represent and are composed of member states. Even the UN Convention Against Corruption (UNCAC) which represents the most recent international agreement did not address issues of state capture or political corruption (with the exception of political finance). State capture and political corruption dominate many developing regions.

Additionally, even though political corruption and its determinants impact a chain of variables that influence growth indicators/contributors, they are the most difficult to address and change. In the presence of undemocratic and politically corrupt regimes, especially in the cases of state capture as it is the situation in numerous of Middle East and African countries (past and present), it would not make sense to request from the capturing and corrupting elites to give up their power or to introduce true political reforms. Such changes would mean relinquishing the huge benefits they are extracting. The parties that need to be addressed are the people themselves. And, the irony is that international organizations deal with state governments not people which are the real dilemma of addressing political and state capture corruption.

The prevalence of macro corruption does not only indicate its systemic nature but it also signifies that strategic institutions of the society determining its development and welfare are captured by elite groups and are manipulated and directed to serve their self-interests. The micro analysis of corruption offers little direction when such strategic institutions are infected by corruption. Macro corruption operates at the total state and societal systems. Therefore, when it is infecting and penetrating these systems, its economic development consequences and causes provides a more powerful analytical tools for better understanding of and addressing the more serious, systemic and strategic level corruption; macro corruption.

Currently, the literature on anti-corruption can be classified into overall, sector and micro/institutional approaches. The overall approach deals with what can be tackled at the macro level (e.g. governance and administrative reform, political reform, legislative reform and economic reform). The overall approach is not based on analysis and diagnosis at the macro level. The proposed framework attempts to fill this gap by providing correspondence between types of macro corruption, their forward and backward linkages and how they operate to enable the assessment of the infected domains along with their consequences to enable setting the strategies that correspond to this analysis and diagnosis. More importantly, by focusing on the factors/causes of the various types of macro corruption, attention is drown to what need to be done to cure the existing gaps in these causes. The sectorial approach suggests analyzing corruption and deriving combating strategies according to the nature and particularities of the sector and the corruption risks and prevalence associated with it. It is a good strategy if corruption at the macro level is relatively weak. In the opposite case the sectorial corruption is due to macro governance gaps that cannot be addressed at the sectorial level only. Similarly, the micro/institutional approach is effective if corruption is confined to particular organizations or micro types. It is not an effective cure if is applied with no provision to how widespread corruption is beyond the particular institutions or types and with no consideration to macro corruption prevalence. In many cases international organizations and most of the community of anticorruption experts promote these approaches as the macro corruption types and the related 
anticorruption strategies have been mostly beyond the realm of systematic corruption analysis and diagnosis.

A major difference between macro and micro corruption is that the first (with exception of the aggregate bureaucratic type) is not designed to get around the rules; rather it creates the rules that benefit the corrupt elites. As Khan (2006) has observed, this is why policy prescriptions taken from the experience of countries with strong laws and institutions (and strong democratic accountability systems) have been proven to be inappropriate for highly corrupt poor countries. The reason is that these countries along with resource rich/curse countries primarily suffer from macro corruption; the state and the political system are captured, the government bureaucracy is highly infected by corruption and the financial sector/institutions and the corporate sector are full of speculative and rent seeking activities. The impact of macro corruption is much graver that the micro corruption. Besides weakening state and societal systems and institution and capturing their compass. It greatly weakens the legitimacy of these systems and institutions and loots and destroys people's future and dreams. Corruption at the macro level suppresses growth and development and creates inequity, while at the micro level it may coexist with growth. This is why the debate on the relationship between corruption (micro level measured by perception) and growth measures has taken opposite direction.

The proposed framework in this paper suggests going beyond the role of the state and other societal institutions in addressing and confronting macro corruption. In many such cases, the prescription of international institutions and the related literature addressing corruption would be greatly inadequate in the case of macro corruption. Strategic changes pertinent to causes of macro corruption would be needed, including the possibility of toppling state and societal systems and institutions. That change could only be achieved through popular uprising and revolutions led by benevolent groups. In these countries, internal political conflict and rivalry is often high; political factions compete for their share in the society's assets and in the macro proceedings derived from controlling the state policies and key and lucrative sectors in the economy. In such cases, simple-minded solutions such as providing accountability and transparency as a remedy for corrupted sectors/agencies would not work, because the whole societal system is infected by corruption. No wonder that effective and long-lasting corruption control is a rare and precious achievement because the roots of the problem (the power and institutional structure) in the country penetrated by macro corruption stays the same. It can only happen in the case of well determined, benevolent and intelligent political and institutional reform backed by popular support and surveillance.

\section{Conclusions}

We have advanced an argument for the macro analysis of corruption and its economic developmental consequences (or forward linkages) and institutional determinants (or backward linkages), by suggesting a conceptual framework that clarifies these linkages. We differentiated between four types of macro corruption: state capture, political, bureaucratic and financial/corporate. This level of analysis has major implications for the research on corruption not only with regard to the type of variables and their linkages but also with regard to the type of measures and data that need to be developed to serve this macro perspective. At 
present, there is a paucity of measures and data on corruption and its linkages that supports research at this macro level.

This is much needed to understand the complex and interwoven connections and dynamics by which corruption evolves and impacts. New measures need to be developed to enable researchers, reformists and benevolent policy makers alike to address issues and problems related to macro corruption. Lack of information on such aspects hinders research and reforms that is directed, for example, to reduce the burden of corruption on the poor and to improve economic growth, equity, inclusiveness and sustainability.

\section{Acknowledgement}

The authors would like to thank Mohamed Abdelmoniem Khamis for the word processing the manuscript and editing and proof reading the references.

\section{References}

Acemoglu, D., \& Verdier, T. (1998). Property rights, corruption and the allocation of talent: A general equilibrium approach. Economic Journal, 108, 1381-1403. https://doi.org/10.1111/1468-0297.00347

Aidt, S. (2003). Economic analysis of corruption: A survey. Economic Journal, 113, 632- 652. https://doi.org/10.1046/j.0013-0133.2003.00171.x

Aidt, S. (2009). Corruption, institutions and economic development. Working Papers in Economics 0918. https://doi.org/10.1093/oxrep/grp012

Aidt, S. (2010). Corruption and sustainable development. Cambridge. Working Papers in Economics 1061, Faculty of Economics, University of Cambridge.

Aidt, S., Dutta, J., \& Sena, V. (2005). Growth, governance and corruption in the presence of threshold effects: Theory and evidence. Cambridge Working Papers in Economics. Cambridge: University of Cambridge.

Aidt, S., Dutta, J., \& Sena, V. (2008). Governance regimes, corruption and growth: Theory and evidence. Journal of Comparative Economics, 36(2), 195-220. https://doi.org/10.1016/j.jce.2007.11.004

Ake, C. (1996). Democracy and development in Africa. Washington, D.C: Brookings Institution.

Andrig, C., \& Moene, O. (1990). How corruption may corrupt. Journal of Economic Behavior and Organization, 13(1), 63-76. https://doi.org/10.1016/0167-2681(90)90053-G

Atkinson, G., \& Hamilton, K. (2003). Saving, Growth and the resource curse hypothesis. World Development, 31, 1793-1807. https://doi.org/10.1016/j.worlddev.2003.05.001

Auty, M. (1993). Sustaining development in mineral economies. London: Routledge.

Bardhan, P. (1997). Corruption and development: A review of issues. Journal of Economic Literature, 45, 1320-1346. 
Beck, P., \& Maher, M. (1986). A Comparison of bribery and bidding in thin markets. Economics Letters, 20(1), 1-5. https://doi.org/10.1016/0165-1765(86)90068-6

Blackburn, K., Niloy, B., \& Emranul H. (2008). Endogenous corruption in economic development. Unpublished Working Paper, Department of Economics, University of Wisconsin.

Blackburn, K., Niloy, B., \& Emranul, H. (2006). The incidence and persistence of corruption in economic development. Journal of Economic Dynamics and Control, 30, 2447- 2467. https://doi.org/10.1016/j.jedc.2005.07.007

Broadman, H., \& Recanatini (2001). Seeds of corruption: Do market institutions matter? MOCT-MOST, (11), 359-392. https://doi.org/10.1023/A:1015264312632

Conceicao, P., Shimeles, A., \& Solignac-Lecomte, H. (2014). Are global value chains good news for Africa's industrialization. Great Insights, 3(5). Retrieved from: https://ecdpm.org/great-insights/value-chains-industrialisation/global-value-chains-good-new s-africas-industrialisation/

Drury, C., Krieckhaus, J., \& Lusztig, M.(2006). Corruption, democracy, and economic growth. International Political Science Review, 27(2), 121-136. https://doi.org/10.1177/0192512106061423

Ellis, J., \& Fender, J. (2006). Corruption and transparency in a growth model. International Tax and Public Finance, 13(2-3), 115-149. https://doi.org/10.1007/s10797-006-1664-z

Groenendijk, N. (1997). A principal-agent model of corruption. Crime, Law \& Social Change, 27, 207-229. https://doi.org/10.1023/A:1008267601329

Gylfason, T. (2001). Natural resources, education and economic development. European Economic Review, 45, 847-859. https://doi.org/10.1016/S0014-2921(01)00127-1

Hodge, A., Shankar, S., Rao, D., \& Duhs, A. (2011). Exploring the links between corruption and growth. Review of Development Economics, 15(3), 474-490. https://doi.org/10.1111/j.1467-9361.2011.00621.x

Hodler, R. (2006). The curse of natural resources in fractionalized countries. European Economic Review, 50, 1367-1386. https://doi.org/10.1016/j.euroecorev.2005.05.004

Humphreys, M., \& Bates, R. (2005). Political institutions and economic policies: Lessons from Africa. British Journal of Political Science, 35, 403-428. https://doi.org/10.1017/S0007123405000232

Huntington, P. (1968). Political Order in Changing Societies. New Haven, Conn.: Yale University Press.

Ianchovichina, E., \& Lundstrom, S. (2009). Inclusive growth analytics: Framework and Application. Policy Research working paper; no. WPS 4851. Washington, DC: World Bank.

Kaufmann, D. (1997). Corruption: The facts. Foreign Policy, 107, 114-131. 
https://doi.org/10.2307/1149337

Kaufmann, D., \& Wei, S. (1999). Does "grease money" speed up the wheels of commerce? National Bureau of Economic Research, Inc., NBER Working Papers: 7093. https://doi.org/10.3386/w7093

Khan, M. (2006) Determinants of corruption in developing countries: The limits of conventional economic analysis, In S. Rose-Ackerman (ed.), International handbook on the economics of corruption. Northampton, MA: Edward Elgar.

Krusell, P., \& Rios-Rull, J. (1996). Vested interests in a positive theory of stagnation and growth. Review of Economic Studies, 63, 301-329. https://doi.org/10.2307/2297854

Lane, R., \& Tornell, A. (1996). Power, growth, and the voracity effect. Journal of Economic Growth, 1(2), 213-41. https://doi.org/10.1007/BF00138863

Leff, N. (1964). Economic development through bureaucratic corruption. American Behavioral Scientist, 8(3), 8-14. https://doi.org/10.1177/000276426400800303

Leith, C., \& Lofchie, M. (1991). The Case of Ghana. Economic and Political Interactions in Economic Policy Reform (eds.) in R. Bates and A. Krueger. Oxford: Blackwell.

Lui, T. (1985). An equilibrium queuing model of bribery. Journal of Political Economy, 93(4), 760-781. https://doi.org/10.1086/261329

Mauro, P. (1995). Corruption and growth. Quarterly Journal of Economics, 110, 681-712.

Mauro, P. (1997). The effects of corruption on growth, investment, and government expenditure: A cross-country analysis. In K. Elliott (eds.), Corruption and the Global Economy (pp. 83- 107). Washington, D.C.: Institute for International Economics. https://doi.org/10.2307/2946696

Mauro, P. (1998). Corruption and composition of government expenditure. Journal of Public Economics, 69, 263-279. https://doi.org/10.1016/S0047-2727(98)00025-5

Mazzucato, M. (2018). The value of everything: Making and taking in the global economy. London: Allen Lane.

Mehlum, H., Karl, M., \& Ragnar, T. (2006). Institutions and the resource curse. Economic Journal, 116(508) 1-20. https://doi.org/10.1007/978-3-540-79247-5_13

Mo, H. (2001). Corruption and economic growth. Journal of Comparative Economics, 29, 66-79. https://doi.org/10.1006/jcec.2000.1703

Murphy, M., Andrei S., \& Robert V. (1993). Why is rent seeking so costly to growth? American Economic Review, Paper and Proceedings, 83, 409-414.

Murphy, M., Andrei, S., \& Robert, V. (1991). The allocation of talent: Implications for growth. Quarterly Journal of Economics, 106, 503-530. https://doi.org/10.2307/2937945

Myrdal, G. (1968). Asian Drama: An Inquiry into the Poverty of Nations. New York: 
Twentieth Century Fund.

Papurakis, E., \& Reyer, G. (2006). Resource windfalls, investment, and long-term income. Resource Policy, 31, 117-1128. https://doi.org/10.1016/j.resourpol.2006.09.002

Pellegrini, L., \& Gerlagh, R. (2004). Corruption's effect on growth and its transmission channels. Kyklos, 57, 429-456. https://doi.org/10.1111/j.0023-5962.2004.00261.x

Pritchett, L., \& Werker, E. (2012). Developing the guts of a GUT (Grand Unified Theory): Elite commitment and inclusive growth. ESID Working Paper Series 16/12. https://doi.org/10.2139/ssrn.2386617

Robinson, A., \& Torvik, R., \& Verdier, T. (2006). Political foundations of the resource curse. $\begin{array}{llll}\text { Journal of Development } & \text { Economics, } & 79, & \text { 447-468. }\end{array}$ https://doi.org/10.1016/j.jdeveco.2006.01.008

Rose-Ackerman, S. (1999). Corruption and government, causes, consequences and reform. Cambridge UK: Cambridge University Press. https://doi.org/10.1017/CBO9781139175098

Seyf, A. (2001). Corruption and development: A study of conflict. Development in Practice, 11(5), 597-605. https://doi.org/10.1080/09614520120085340

Tanzi, V. (1998). Corruption around the world: Causes, consequences, scope and cures. IMF Staff Papers, 45(4), 559-594. https://doi.org/10.2307/3867585

Ugur, M., \& Dasgupta, N. (2011). Evidence on the economic growth impacts of corruption in low income countries and beyond: A systematic review. London: EPPI-Centre, Social Science Research Unit, Institute of Education, University of London.

Venard, B. (2013). Institutions, corruption and sustainable development. Economic Bulletin, $33(4), 2545-2562$.

WCED (World Commission on Environment and Development) (1987). Our Common Future: Report of the World Commission on the Environment and Development [Bruntlandt Report]. General Assembly, United Nations, Forty-second Session, Supplement No. 25, A/42/25.

Wei, S. (2000). How taxing is corruption on international investors? Review of Economics and Statistics, 82(1), 1-11. https://doi.org/10.1162/003465300558533

World Bank (2010). Literature survey on state capture, grand corruption and political corruption. Public Sector Governance, Poverty Reduction \& Economic Management (PREM).

\section{Copyright Disclaimer}

Copyright for this article is retained by the author(s), with first publication rights granted to the journal.

This is an open-access article distributed under the terms and conditions of the Creative Commons Attribution license (http://creativecommons.org/licenses/by/4.0/). 